\title{
Conditional Heteroskedasticity and Cross-sectional Dependence in Panel MGARCH: Exchange Rate and Stock Market Uncertainty
}

Mansour Tour ( $\square$ tour_mansour@yahoo.com )

Semnan University Faculty of Economics Management and Administrative Sciences https://orcid.org/0000-0002-1279-072X

Esmaiel Abounoori

Semnan University

\section{Research}

Keywords: Panel Multivariate GARCH, Exchange rate, Stock index, UK, Canada, China

Posted Date: May 20th, 2021

DOI: https://doi.org/10.21203/rs.3.rs-510661/v1

License: (c) (1) This work is licensed under a Creative Commons Attribution 4.0 International License.

Read Full License 


\title{
Conditional Heteroskedasticity and Cross-sectional Dependence in Panel MGARCH: Exchange Rate and Stock Market Uncertainty
}

\author{
Mansour Tour ${ }^{1}$ (Corresponding Author) and Esmaiel Abounoori ${ }^{2}$ \\ ${ }^{1}$ Economic Department, Semnan University, Semnan-Iran \\ tour_mansour@yahoo.com \\ ${ }^{2}$ Economic Department, Semnan University, Semnan-Iran \\ esmaiel.abounoori@semnan.ac.ir
}

\begin{abstract}
Despite lots of research concerning different GARCH and Panel-GARCH as well as MGARCH models, we have not seen Panel MGARCH so far reviewing literatures. Though there are spillover effects between crosssections for one variable, there may be spillover effects and cross-sections dependence for several variables too. The main aim in this research is to use the Panel MGARCH (P-MGARCH) model regarding weekly exchange rate and the stock market index across countries UK, Canada and China during 2010: 10 to 2020: 08. According to the results, the volatility spillover among cross-sections (UK, China and Canada) for variables (Exchange rates and Stock exchange returns) has been confirmed.
\end{abstract}

Keywords: Panel Multivariate GARCH, Exchange rate, Stock index, UK, Canada, China

JEL Classification: C33, C58, F30

\section{Introduction}

Financial markets consist of the money market and the capital market. Financing short-term resources is one of the main tasks of the money market, while financing long-term resources and allocating it to economic firms is organized by the capital market.

The expansion of foreign investment in financial markets and trade between countries are considered as important reasons for interactions and connections between world financial markets. Globalization and the growth of information technology have greatly increased the interactions between financial markets.

The development of financial markets and financial systems growth is positively related to economic growth (Mckinnon and Shaw, 1973; Schumpeter, 1911; King and Levine, 1995). One of the basic requirements for the development of financial markets is to maintain the relative stability of these markets against shocks and volatility of domestic and foreign source.

The size and amount of volatility in financial markets is an important criterion for measuring the degree of stability in financial markets, so knowing the amount of shock and volatility and the type of relationship in financial markets is very important for investors and policymakers in these markets.

Investigating the mechanism of receiving and transmitting shocks and volatility in foreign exchange and stock markets provides effective and valuable information to investors, policymakers and the central bank. This information is used by investors in investment decisions and selection of portfolios and policymakers to control and stabilize these markets.

To measure the volatility and conditional correlation of time series, conditional heteroskedasticity models were introduced. For the first time, Engle (1982) and Bollerslev (1986) introduced patterns of conditional heteroskedasticity to model volatility of time series. Then the possibility of modeling, measuring and analyzing the amount of volatility spillover between several time series in multivariate GARCH models of VECH (Bollerslev, Engle, \& 
Wooldridge, 1988), BEKK (Engle and Kroner, 1995), CCC (Bollerslev, 1990), DCC (Engle, 2002) and DECO (Engel and Kelly, 2012) was provided.

These models evaluate a time series volatility or several time series variance-covariance regardless of the dependence of the cross-sections (Kanas, 1998; Flavin and Wickens, 2001; Worthington and Higgs, 2004; Hamuo, Masulis and Ng, 2006; Hammoudeh, Yuan and McAleer, 2010; Baybogan, 2013; Hachula and Hoffmann, 2015; Gu, Liu and Weng, 2017; Abounoori and Tour, 2019; Zivkov et al, 2020).

Higher degrees of freedom, more flexibility, higher efficiency and the possibility of measuring the degree of dependence of the cross-sections are the advantages of panel data models. Sermeno and Grier (2006) developed GARCH model to panel GARCH model to investigate conditional heteroskedasticity of inflation and cross-sectional dependence in G7 countries. In recent years, various studies have been performed using panel GARCH model to evaluate conditional variance and cross-sectional dependence (Lee, 2010; Ribeiro, Sermeno \& Curto, 2017; Arneric \& Peric, 2018; Bathia et al., 2020).

In order to identify and calculate time-varying variance-covariance dependence in the panel data, the dimensions of the cross-sections should be small enough so that we do not face the limitation of using this type of model by rapidly increasing the parameters as the number of cross-sections grows.

Although in conditional heteroskedasticity models of panel GARCH, it is possible to measure the dependence of cross-sections for only one variable (time series), but these models are not able to estimate the amount of volatility spillover between cross-sections for several time series. In this paper in order to overcome this limitation, by developing Sermeno and Grier (2006) panel GARCH model, we suggest a multivariate panel GARCH model to simultaneously estimate the volatility spillover between cross-sections for several time series.

\section{Review of literature}

In the field of communication channels between foreign exchange and stock markets, there are two major approach groups. Based on the "flow-oriented and the international trading effect" approach, when the foreign exchange rate rises, the competitiveness of the country's export sector grows, domestic products become cheaper for foreigners, and the profits of export firms increase, which leads to an increase in the stock prices of these firms (Dornbusch and Fischer, 1980; Aggarwal, 1981).

In the context of the "portfolio balance" approach, the stock market growth on the one hand directs a part of the domestic liquidity to this market and on the other hand increases the activity of foreign investors in this market, which will lead to an increase in domestic money demand and a decrease in the exchange rates (Branson and Henderson, 1985).

The Multivariate GARCH (MGARCH) model and panel data have been used to estimate volatility spillovers own-effects and cross-effects in financial markets and macroeconomics. Kanas (1998) examined the volatility spillovers between European stock markets using the bivariate EGARCH model and London stock market daily data (FTSE), Frankfurt (FAZGeneral) and Paris (CAC-General) from 1984 to 1993. He concluded that there was a bilateral volatility spillover between the London and Paris stock markets, as well as between the Paris and Frankfurt stock markets. Also there was a unilateral volatility spillover from the London stock market to the Frankfurt stock market. Worthington and Higgs (2004) evaluated the process of volatility spillover between Southeast Asian stock markets. In this study, the multivariate GARCH model was estimated using developed countries weekly data: Hong Kong, Japan, Singapore and six emerging countries Korea, Indonesia, Malaysia, Philippines, Thailand and Taiwan, in period 1988 to 2000. They showed: 1) there is a high degree of 
convergence and correlation between these markets. 2) The effects are different among emerging markets compared to advanced markets. 3) The volatility spillovers own-effects are higher than cross-effects for all markets. Abounoori and Tour (2019) examined the interactions between the stock markets of Iran, the United States, Turkey and the United Arab Emirates using the multivariate GARCH model and Diebold and Yilmaz (2012) index. Due to the relatively very large size of the US economy, no spillovers effects have been observed from any other country on US stock market. The spillover index of Diebold and Yilmaz (2012) show that the interactions between these markets have been significant. Zivkov et al (2020) examine the impact of inflation and its uncertainty on GDP growth in eight Central and Eastern European countries. After extracting the inflation uncertainty series using GARCH model, Bayesian quantile model was estimated. The results show that the effect of inflation is much less than its uncertainty effect on GDP growth, which confirms Friedman's theory.

In order to investigate the relationships between financial markets, a number of studies were performed using the panel GARCH model. Lee (2010) using the panel GARCH model, examined relationship between production growth and volatility in the G7 countries. He concluded that higher production growth would lead to more volatility of innovations for production growth. Arneric, and Peric (2018) using the panel GARCH model, examined the degree of dependence between the stock markets of 10 emerging European countries. The results show that there are Monday effects in the equations of mean and variance, but the Tuesday effects are only in the mean equation. The results also indicate the cross-sections dependence in this period. Hassani et al (2019) forecasted UK interest rate volatility using 150-year data and different univariate GARCH models. The results showed that GARCH models with the generalized error distribution for short, medium and long term have the most accurate UK interest rate forecast. Bathia et al (2020) examined the effects of cross-border capital flows on the stock markets of nine emerging countries using the panel GARCH model. They showed that capital flows affect the stock markets of these countries. These markets have become more sensitive to capital flows after the great credit crisis.

Though there are spillover effects between different cross-sections (countries) for one variable, there may be spillovers effects among different cross-sections for several variables too. Therefore, the present study introduces panel MGARCH model and uses the advantages of this type of model such as higher degrees of freedom, more flexibility and control over the effects of omitted or unobserved variables and increasing estimation accuracy. In this research, by identifying and calculating the effects of shock and volatility within each market and between markets (currency and stock markets of the United Kingdom, Canada and China), the possibility of using these results by investors, policy makers and planners in financial markets is provided and a step is being taken towards financial development as one of the necessities of economic growth.

\section{Methodology}

Sermeno and Grier (2006) panel GARCH model, assuming the ARMA $(1,1)$ mean equation is as follows:

$$
\begin{array}{lr}
y_{i t}=\alpha_{i}+\beta_{1} y_{i, t-1}+\beta_{2} u_{i, t-1}+u_{i t}, & i=1, \ldots, N, t=1, \ldots, T \\
\sigma_{i t}^{2}=\lambda_{i}+\delta_{1} u_{i, t-1}^{2}+\delta_{2} \sigma_{i, t-1}^{2}, & i=1, \ldots, N
\end{array}
$$


$\sigma_{i j t}=\eta_{i j}+\mu_{11} u_{i, t-1} u_{j, t-1}+\mu_{12} \sigma_{i j, t-1} \quad i \neq j$

Through the development of Sermeno and Grier (2006) panel GARCH model to the panel MGARCH model, the panel mean equations with fixed effects for 2 variables and 3 crosssections are defined as follows:

$$
\begin{aligned}
& x_{i t}=\alpha_{1 i}+\beta_{11} x_{i t-1}+\beta_{12} y_{i t-1}+\beta_{13} u_{x, i t-1}+\beta_{14} u_{y, i t-1}+u_{x, i t} \\
& y_{i t}=\alpha_{2 i}+\beta_{21} x_{i t-1}+\beta_{22} y_{i t-1}+\beta_{23} u_{x, i t-1}+\beta_{24} u_{y, i t-1}+u_{y, i t}
\end{aligned}
$$

Which $\alpha$ is the vector of the cross-sections effects, $x_{i t}$ and $y_{i t}$ are the exchange rate and stock price return in country $i, \beta$ is the coefficients vector, $u$ is the disturbance terms vector with zero mean, normal distribution, and the conditional moments as follows:

$$
\begin{aligned}
& \mathrm{E}\left[u_{x, i t} u_{x, j s}\right]=0 \quad \mathrm{E}\left[u_{y, i t} u_{y, j s}\right]=0 \quad \text { for } i \neq j \text { and } t \neq s \\
& \mathrm{E}\left[u_{x, i t} u_{x, j s}\right]=0 \quad \mathrm{E}\left[u_{y, i t} u_{y, j s}\right]=0 \quad \text { for } i=j \text { and } t \neq s \\
& \mathrm{E}\left[u_{x, i t} u_{x, j s}\right]=\sigma_{x, i t}^{2} \mathrm{E}\left[u_{y, i t} u_{y, j s}\right]=\sigma_{y, i t}^{2} \quad \text { for } i=j \text { and } t=s \\
& \mathrm{E}\left[u_{x, i t} u_{x, j s}\right]=\sigma_{x, i j t} \quad \mathrm{E}\left[u_{y, i t} u_{y, j s}\right]=\sigma_{y, i j t} \quad \text { for } i \neq j \text { and } t=s \\
& \mathrm{E}\left[u_{x, i t} u_{y, j s}\right]=\sigma_{x i y i, t} \quad-\quad \text { for } i=j \text { and } t=s \\
& \mathrm{E}\left[u_{x, i t} u_{y, j s}\right]=\sigma_{x i y j, t} \quad \text { for } i \neq j \text { and } t=s
\end{aligned}
$$

Assumptions: relations (6) indicate lack of serial autocorrelation of disturbance terms between cross-sections (countries), relations (7) assume lack of serial autocorrelation of disturbance terms in each cross-section (country), relations (8) show conditional variance in each cross-section, relations (9) are conditional covariance between cross-sections (countries) for $\mathrm{x}$ series or $\mathrm{y}$ series, relation (10) indicates correlation between series ( $\mathrm{x}$ and $\mathrm{y}$ ) with the same cross-section (one country) and relation (11) shows correlation between series ( $\mathrm{x}$ and $\mathrm{y}$ ) with different cross-sections (two countries). In this study, it is assumed that the equations of conditional variance-covariance of the series follow the $\operatorname{GARCH}(1,1)$ model as follows:

$$
\begin{aligned}
& \sigma_{x i, t}^{2}=\lambda_{1 i}+\delta_{11} u_{x i, t-1}^{2}+\delta_{12} \sigma_{x i, t-1}^{2}+\delta_{13} u_{y i, t-1}^{2}+\delta_{14} \sigma_{y i, t-1}^{2}+\delta_{15} u_{x i, t-1} u_{y i, t-1}+\delta_{16} \sigma_{x i y i, i t-1} \\
& \sigma_{y i, t}^{2}=\phi_{1 i}+\gamma_{11} u_{x i, t-1}^{2}+\gamma_{12} \sigma_{x i, t-1}^{2}+\gamma_{13} u_{y i, t-1}^{2}+\gamma_{14} \sigma_{y i, t-1}^{2}+\gamma_{15} u_{y i, t-1} u_{x i, t-1}+\gamma_{16} \sigma_{y i x i, i t-1} \\
& \sigma_{x i x j, t}=\eta_{i j}+\mu_{11} u_{x i, t-1} u_{x j, t-1}+\mu_{12} \sigma_{x i x j, t-1}+\mu_{13} u_{y i, t-1} u_{y j, t-1}+\mu_{14} \sigma_{y i y j, t-1} \\
& \sigma_{y i y j, t}=\chi_{i j}+\varphi_{11} u_{x i, t-1} u_{x j, t-1}+\varphi_{12} \sigma_{x i x j, t-1}+\varphi_{13} u_{y i, t-1} u_{y j, t-1}+\varphi_{14} \sigma_{y i j, t-1} \\
& \sigma_{x i y i, t}=l_{i i}+v_{11} u_{x i, t-1}^{2}+v_{12} \sigma_{x i, t-1}^{2}+v_{13} u_{y i, t-1}^{2}+v_{14} \sigma_{y i, t-1}^{2}+v_{15} u_{x i, t-1} u_{y i, t-1}+v_{16} \sigma_{x i y i, t-1} \\
& \sigma_{x i y j, t}=\vartheta_{i j}+\theta_{11} u_{x i, t-1}^{2}+\theta_{12} \sigma_{x i, t-1}^{2}+\theta_{13} u_{y j, t-1}^{2}+\theta_{14} \sigma_{y j, t-1}^{2}+\theta_{15} u_{x i, t-1} u_{y j, t-1}+{ }_{\theta_{16}} \sigma_{x i y j, t-1}
\end{aligned}
$$

The mean equations (4) and (5) are rewritten as the following matrix:

$$
Z_{t}=\alpha+Z_{t-1} \beta+u_{t}
$$

In which $z_{t}=\left[x_{t}, y_{t}\right]^{\prime}, z_{t-1}=\left[x_{t-1}, y_{t-1}, u_{x t-1}, u_{y t-1}\right], u_{t}=\left[u_{x t}, u_{y t}\right]^{\prime}, \beta=\left[\beta_{1} \vdots \beta_{2}\right]^{\prime}$, $\beta_{1}=\left[\beta_{11}, \beta_{12}, \beta_{13}, \beta_{14},\right]^{\prime}$ and $\left.\beta_{2}=\left[\beta_{21}, \beta_{22}, \beta_{23}, \beta_{24},\right]^{\prime}\right), \quad \alpha=\left[\alpha_{1}, \alpha_{2}\right]^{\prime}$ and $u_{t}$ is the disturbance terms vector which has a normal bivariate distribution $\left(u_{t} \sim N\left(0, \Omega_{t}\right)\right)$. The diagonal elements and off-diagonal of the matrix $\Omega_{t}$ show conditional variance (Equations in relation (8)) and conditional covariance (Equations in relations (9), (10) and (11)), 
respectively. The conditional density function of two variables of time series is written as follows:

$$
f\left(u_{t} \mid Z_{t-1}, \alpha, \beta, \phi\right)=(2 \pi)^{-N / 2}\left|\Omega_{t}\right|^{-1 / 2} \exp (-1 / 2)\left(Z_{t}-\alpha-Z_{t-1} \beta\right)^{\prime} \Omega_{t}^{-1}\left(Z_{t}-\alpha-Z_{t-1} \beta\right)
$$

In which $\phi$ is the parameters of the equations of variance-covariance and $\mathrm{N}$ is equal to the number of cross-sections multiplied by the number of time series. The log-likelihood function of the data panel with fixed effects and the time-varying conditional variance-covariance matrix are as follows:

$$
l=-\frac{N T}{2} \ln (2 \pi)-\frac{1}{2} \sum_{t=1}^{T} \ln \left|\Omega_{t}\right|-\frac{1}{2} \sum_{t=1}^{T}\left[\left(Z_{t}-\alpha-Z_{t-1} \beta\right)^{\prime} \Omega_{t}^{-1}\left(Z_{t}-\alpha-Z_{t-1} \beta\right)\right]
$$

Using the maximum log-likelihood method used by Cermeno and Grier (2006), in addition to overcoming the inefficiency of the ordinary least squares estimation method due to the heteroskedasticity of disturbance terms and cross-sectional dependence in panel model, relation (20) is efficiently estimated and volatility spillovers between cross-sections (countries) as well as variables are identified. The prominent feature of the present paper is that by introducing panel MGARCH model, the direction and intensity of volatility spillover between several variables (time series) and several cross-sections (countries) can be calculated, while in panel GARCH model, can be estimated volatility spillover between only one variable and several cross-sections. Thus the capability of this model can be used in researches related to financial markets volatility, macroeconomics, international economics and

other

fields.

\section{Data and model \\ 4.1 Data}

The data in this study are the weekly time series of exchange rates ${ }^{1}$ and stock prices ${ }^{2}$ of 3 countries, UK, Canada and China in the form of logarithmic growth from 2010: 10 to 2020: 08. The select of stock and foreign exchange markets is based on the size of the economies of countries, because these economies are more important on an international scale due to their significant connections and interactions with most countries (GDP and total exports and imports in China are $\$ 14,555$ billion and $\$ 5,117$ billion, respectively, and in the United Kingdom are $\$ 2,776$ billion and $\$ 1,161$ billion, respectively) ${ }^{3}$. Due to the dollar was used as the base currency and it was not possible to use US exchange rate data, Canada data was used due to its neighborhood to the US and the relatively large economy of this country (Canada's gross domestic product and total exports and imports are $\$ 1,743$ billion and $\$ 899$ billion, respectively $)^{4}$. Also, the sample period was considered 10 years based on the two criteria of maintaining the relative stability of the model coefficients and using sufficient data to estimate the model.

\footnotetext{
1 - https://finance.yahoo.com. https://www.investing.com.

2 - https://finance.yahoo.com

3 - https://www.macrotrends.net. https://globaledge.msu.edu. https://data.worldbank.org.

4 - https://www.macrotrends.net. https://globaledge.msu.edu.
} 
Table 1 . The weekly market return statistic in UK, Canada and China.

\begin{tabular}{ccccccc}
\hline \multirow{2}{*}{$\begin{array}{c}\text { Statistical } \\
\text { Indices }\end{array}$} & \multicolumn{3}{c}{ Exchange } & & \multicolumn{3}{c}{ stock } \\
\cline { 2 - 6 } & $\mathrm{UK}(\mathrm{X} 1)$ & $\mathrm{CAN}(\mathrm{X} 2)$ & $\mathrm{CHA}(\mathrm{X} 3)$ & $\mathrm{UK}(\mathrm{Y} 1)$ & $\mathrm{CAN}(\mathrm{Y} 2)$ & $\mathrm{CHA}(\mathrm{Y} 3)$ \\
\hline Mean & -0.000387 & -0.000505 & $-6.23 \mathrm{E}-05$ & 0.000115 & 0.000512 & 0.000381 \\
Median & -0.000321 & -0.000384 & 0.000156 & 0.001931 & 0.001666 & 0.001289 \\
Maximum & 0.048817 & 0.031700 & 0.017825 & 0.075921 & 0.094088 & 0.090738 \\
Minimum & -0.097692 & -0.047638 & -0.037433 & -0.185921 & -0.280219 & -0.142910 \\
Std. Dev. & 0.012824 & 0.010655 & 0.005181 & 0.022040 & 0.021679 & 0.028648 \\
Skewness & -1.364942 & -0.213199 & -1.018558 & -1.589393 & -4.109722 & -0.687093 \\
Kurtosis & 14.52082 & 3.809177 & 9.433696 & 14.92732 & 57.20126 & 6.294056 \\
Jarque-Bera & 3037.267 & 18.12594 & 986.7495 & 3301.255 & 65115.60 & 276.0159 \\
Probability & 0.000000 & 0.000116 & 0.000000 & 0.000000 & 0.000000 & 0.000000 \\
\hline
\end{tabular}

Source: Calculations based on the weekly return data of the exchange and stock indices

Table (1) reflects the following information; Weekly exchange rate return mean and stock in all markets are negative and positive, respectively. Highest stock return mean has happened in Canada (0.000512). The standard deviation of stock return is relatively higher than the standard deviation of exchange rate returns, which shows relatively more stability in the exchange market. The skewness in all markets are negative and this skewness in the Canada stock market is more than 3 times the stock market of other countries and the exchange markets. Also, the kurtosis of the distribution in all markets is more than the normal distribution, which is consistent with the general empirical evidences. The significance levels corresponding Jarque-Bera statistic reject the normality of the distributions.

Table 2. Unit Root test results.

\begin{tabular}{ccccc}
\hline Variable & Test statistic & prob & Test & Null Hypothesis \\
\hline $\begin{array}{c}\text { exchange rate returns } \\
(\mathrm{X})\end{array}$ & 16.7448 & 0.0000 & Im, Pesaran and & variables have unit \\
root
\end{tabular}

According to the probability, the null hypothesis cannot be accepted at $1 \%$ level

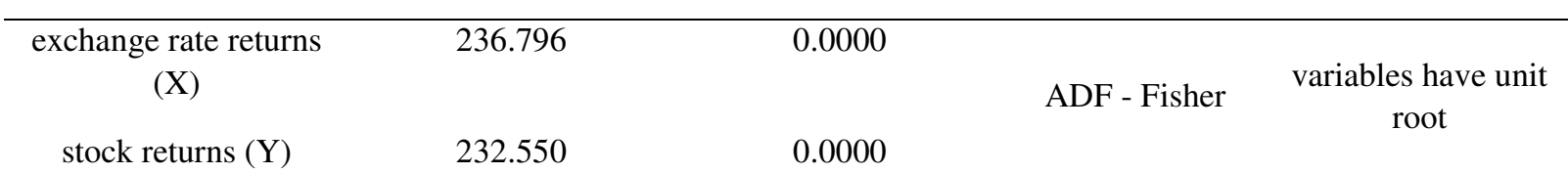

According to the probability, the null hypothesis cannot be accepted at $1 \%$ level

Source: Test of hypothesis using EViews software.

According to the results in Table (2) the panel unit root tests of the Im, Pesaran and Shin, and ADF-Fisher confirm the stationary of the exchange rate and stock returns concerning different countries.

\subsection{Specifying the mean equations and variance-covariance}




\subsubsection{Specifying the mean equations}

Due to the presence of memory in financial time series against time series changes and shocks, each of the mean equations was considered as ARMA model.

Since the number of observations (T) in this study is large enough, in the absence of heteroskedasticity and in the absence of autocorrelation of disturbance terms in crosssections, the least-squares dummy variables estimator (LSDV) of the relations (4) and (5) are consistent; however, in the presence of heteroskedasticity and cross-sectional dependence, this estimator is not considered as the best estimator. In this case, the least-squares dummy variables (LSDV) method with a heteroskedasticity and autocorrelation-consistent (HAC) covariance matrix, used by Newey and West (1987) is applied to panel data. After estimating the model and performing the Wald test $\left(H_{0}: \alpha_{11}=\alpha_{12}=\alpha_{13}\right.$ and $\left.\alpha_{21}=\alpha_{22}=\alpha_{23}\right)$, the results indicate the same effects of cross-sections.

\subsubsection{Specifying variance-covariance equations}

The multivariate Ljung-Box (Hosking, 1980) was used to test the ARCH effects. Based on the results of this test, the existence of time-varying conditional variance-covariance for the mean equations disturbance terms was confirmed (statistics value equal to 265.31). Therefore, the final model for estimation was the multivariate GARCH model.

In order to investigate the existence of individual effects of each country in the equations of variance-covariance, the square of residuals, multiply the residuals of each pair of sections, pair of variables (series) and also dummy variables (as representative of sections) were used (Cermeno and Grier, 2006). The test results (the same effects of sections) confirm the existence of individual and different effects of cross-sections in the equations of variancecovariance. Therefore, the equations of conditional variance- covariance were used as a panel with fixed effects in the final model.

\section{Results and discussion}

The results of estimating the coefficients of the multivariate panel-GARCH model were summarized in Table (3) and (4).

$$
\begin{aligned}
& x_{i t}=\alpha_{1}+\beta_{11} x_{i t-1}+\beta_{12} y_{i t-1}+\beta_{13} u_{x, i t-1}+\beta_{14} u_{y, i t-1}+u_{x, i t} \\
& y_{i t}=\alpha_{2}+\beta_{21} x_{i t-1}+\beta_{22} y_{i t-1}+\beta_{23} u_{x, i t-1}+\beta_{24} u_{y, i t-1}+u_{y, i t}
\end{aligned}
$$

Table 3. Results of mean equations estimation.

\begin{tabular}{cccccccc}
\hline Equation & Coefficient & $\begin{array}{c}\text { Coefficient } \\
\text { value }\end{array}$ & $\begin{array}{c}\text { P- } \\
\text { Value }\end{array}$ & equation & Coefficient & $\begin{array}{c}\text { Coefficient } \\
\text { value }\end{array}$ & $\begin{array}{c}\text { P- } \\
\text { Value }\end{array}$ \\
\hline & $\alpha_{1}$ & -0.019 & $\mathbf{0 . 0 0}$ & & $\alpha_{2}$ & 0.030 & $\mathbf{0 . 0 0}$ \\
$\begin{array}{c}\boldsymbol{c}_{\text {exchange }}^{\text {mean }} \\
\text { equations }\end{array}$ & $\beta_{11}$ & 0.033 & $\mathbf{0 . 0 0}$ & & $\beta_{21}$ & 0.061 & $\mathbf{0 . 0 0}$ \\
& $\beta_{12}$ & 0.035 & $\mathbf{0 . 0 0}$ & $\begin{array}{c}\text { stock mean } \\
\text { equations }\end{array}$ & $\beta_{22}$ & 0.056 & $\mathbf{0 . 0 0}$ \\
& $\beta_{13}$ & 0.034 & $\mathbf{0 . 0 0}$ & $\beta_{23}$ & 0.060 & $\mathbf{0 . 0 0}$ \\
& $\beta_{14}$ & 0.035 & $\mathbf{0 . 0 0}$ & $\beta_{24}$ & 0.056 & $\mathbf{0 . 0 0}$
\end{tabular}

Source: Estimated using the necessary codes written in RATS software by the authors. 
Regarding Table (3), all mean equations coefficients are significant. In mean equations, the coefficients of the stock price equation are significantly higher than the corresponding coefficients in the exchange rate equation; this means that the stock market is relatively more sensitive to price changes, as well as shocks in this market and the exchange market.

Table 4. Results of variance-covariance equations estimation.

\begin{tabular}{|c|c|c|c|c|c|c|c|}
\hline Equation & Coefficient & $\begin{array}{c}\text { Coefficient } \\
\text { value }\end{array}$ & $\begin{array}{c}\text { P- } \\
\text { Value }\end{array}$ & equation & Coefficient & $\begin{array}{c}\text { Coefficient } \\
\text { value }\end{array}$ & $\begin{array}{c}\text { P- } \\
\text { Value }\end{array}$ \\
\hline \multirow{9}{*}{$\begin{array}{c}\text { exchange } \\
\text { variance } \\
\text { equations } \\
\left(\sigma_{x i, t}^{2}\right)\end{array}$} & $\lambda_{11}$ & 1.654 & 0.00 & \multirow{7}{*}{$\begin{array}{c}\text { stock } \\
\text { covariance } \\
\text { equation } \\
\text { between } \\
\text { sections } \\
\text { (countries) } \\
\left(\sigma_{y i y j, t}\right)\end{array}$} & $\chi_{12}$ & 1.252 & 0.00 \\
\hline & $\lambda_{12}$ & 1.150 & 0.00 & & $\chi_{13}$ & 0.261 & 0.00 \\
\hline & $\lambda_{13}$ & 0.074 & 0.00 & & $\chi_{23}$ & 2.285 & 0.00 \\
\hline & $\delta_{11}$ & 0.126 & 0.00 & & $\varphi_{11}$ & 0.110 & 0.00 \\
\hline & $\delta_{12}$ & 0.105 & 0.00 & & $\varphi_{12}$ & 0.137 & 0.00 \\
\hline & $\delta_{13}$ & 0.106 & 0.00 & & $\varphi_{13}$ & 0.367 & 0.00 \\
\hline & $\delta_{14}$ & 0.102 & 0.00 & & $\varphi_{14}$ & 0.321 & 0.00 \\
\hline & $\delta_{15}$ & 0.097 & 0.00 & \multirow{9}{*}{$\begin{array}{c}\text { exchange } \\
\text { and stock } \\
\text { covariance } \\
\text { equation in } \\
\text { each } \\
\text { section } \\
\text { (country) } \\
\left(\sigma_{x i y i, t}\right)\end{array}$} & $l_{11}$ & 0.563 & 0.00 \\
\hline & $\delta_{16}$ & 0.106 & 0.00 & & $l_{22}$ & 0.387 & 0.00 \\
\hline \multirow{9}{*}{$\begin{array}{c}\text { stock } \\
\text { variance } \\
\text { equations } \\
\left(\sigma_{y i, t}^{2}\right)\end{array}$} & $\phi_{11}$ & 5.193 & 0.00 & & $l_{33}$ & 0.219 & 0.00 \\
\hline & $\phi_{12}$ & 4.812 & 0.00 & & $v_{11}$ & -0.042 & 0.00 \\
\hline & $\phi_{13}$ & 8.026 & 0.00 & & $v_{12}$ & 0.079 & 0.00 \\
\hline & $\gamma_{11}$ & -0.151 & 0.00 & & $v_{13}$ & 0.095 & 0.00 \\
\hline & $\gamma_{12}$ & 0.131 & 0.00 & & $v_{14}$ & 0.095 & 0.00 \\
\hline & $\gamma_{13}$ & 0.105 & 0.00 & & $v_{15}$ & 0.076 & 0.00 \\
\hline & $\gamma_{14}$ & 0.109 & 0.00 & & $v_{16}$ & 0.077 & 0.00 \\
\hline & $\gamma_{15}$ & 0.133 & 0.00 & \multirow{6}{*}{$\begin{array}{c}\text { exchange } \\
\text { and stock } \\
\text { covariance } \\
\text { equation } \\
\text { between } \\
\text { sections } \\
\text { (countries) } \\
\left(\sigma_{x i y j, t}\right)\end{array}$} & $\vartheta_{12}$ & 0.496 & 0.00 \\
\hline & $\gamma_{16}$ & 0.139 & $\mathbf{0 . 0 0}$ & & $\vartheta_{13}$ & 0.683 & 0.00 \\
\hline \multirow{4}{*}{$\begin{array}{l}\text { exchange } \\
\text { covariance } \\
\text { equation } \\
\text { between } \\
\text { sections } \\
\text { (countries) }\end{array}$} & $\eta_{12}$ & 0.288 & 0.00 & & $\vartheta_{23}$ & 0.556 & 0.00 \\
\hline & $\eta_{13}$ & 0.176 & 0.00 & & $\theta_{11}$ & 0.087 & 0.00 \\
\hline & $\eta_{23}$ & 0.161 & 0.00 & & $\theta_{12}$ & 0.096 & 0.00 \\
\hline & $\mu_{11}$ & 0.115 & 0.00 & & $\theta_{13}$ & 0.099 & 0.00 \\
\hline
\end{tabular}




\begin{tabular}{cccc|cccc}
\hline Equation & Coefficient & $\begin{array}{c}\text { Coefficient } \\
\text { value }\end{array}$ & $\begin{array}{c}\text { P- } \\
\text { Value }\end{array}$ & equation & Coefficient & $\begin{array}{c}\text { Coefficient } \\
\text { value }\end{array}$ & $\begin{array}{c}\text { P- } \\
\text { Value }\end{array}$ \\
\hline$\left(\sigma_{x i x j, t}\right)$ & $\mu_{12}$ & $\mathbf{0 . 1 1 8}$ & $\mathbf{0 . 0 0}$ & & $\theta_{14}$ & 0.099 & $\mathbf{0 . 0 0}$ \\
& $\mu_{13}$ & $\mathbf{0 . 1 1 4}$ & $\mathbf{0 . 0 0}$ & $\theta_{15}$ & 0.097 & $\mathbf{0 . 0 0}$ \\
& $\mu_{14}$ & $\mathbf{0 . 1 0 8}$ & $\mathbf{0 . 0 0}$ & $\theta_{16}$ & 0.094 & $\mathbf{0 . 0 0}$ \\
& & & & &
\end{tabular}

Source: Estimated using the necessary codes written in RATS software by the authors.

According to Table (4) all variance-covariance equations coefficients are significant. Based on the estimated coefficients of variance equations, the amount of shock and volatility spillover from the exchange market to the stock market (-0.151 and 0.131 , respectively) compared to the shock and volatility spillover from the stock market to the exchange market (0.106 and 0.102 , respectively) is relatively higher, which indicates that the stock market response to changes in the exchange market is significantly higher than the exchange market response to changes in the stock market. Also, based on the individual effects of crosssections (intercepts) of the equations of variance, the amount of volatility and instability in the stock market of these countries is significantly higher than the foreign exchange market.

Own conditional correlation spillover in stock markets is up to 3 times higher than own conditional correlation spillover in exchange markets.

The results of estimating the elements of the variance-covariance matrix is summarized as follows: Volatility and uncertainty in the stock market of these countries is more than the foreign exchange market (about 2 times) which these results correspond to the values calculated for the unconditional variances (Table 1); The intensity of communication (conditional correlation) between the foreign exchange markets of these countries is relatively stronger compared to the stock markets (more than 3 times); As expected, volatility in these markets as well as convergence between these markets have increased significantly during the Europe financial crisis (2011).

\section{Conclusion}

In order to observe not only the spillovers effects among different variables but also different countries, we have used a Panel Multivariate GARCH (P-MGARCH) model, using weekly exchange rate and stock price index data across U.K, Canada and China from 2010: 10 to 2020: 08. The estimation results show that the volatility (and shock) spillover from exchange market to the stock market (within each country) has been relatively higher than its revers. This indicates the significant impact of the exchange market on the stock market. Based on the results of the estimated coefficients of conditional covariance equations, correlation (conditional) and the intensity of communication in stock markets compared to foreign exchange markets depends to a greater extent on the degree of correlation of the previous period in these markets.

The results of estimating the elements of the variance-covariance matrix indicate: 1Uncertainty in the stock market of these countries is more than the foreign exchange. 2- As expected, Volatility in these markets as well as convergence between these markets have increased significantly during the Europe financial crisis (2011).

Finally, in this paper, by identifying the effects of uncertainty spillover and the degree of correlation between currency and stock markets of these countries, as well as calculating the time series of variance-covariance matrix, useful information is provided to investors to diversify assets and policy makers to make appropriate decisions in these markets. 


\title{
Acknowledgements
}

There are no acknowledgements to declare at this stage.

\section{Authors' contributions}

The work is the original contribution by the authors. All authors read and approved the final manuscript.

\section{Funding}

Not available.

\section{Availability of data and materials}

The address of the data source is mentioned in the relevant sections of the article.

\section{Ethics approval and consent to participate}

All the participants that helped in this study did so willingly.

\section{Consent for publication}

The authors agreed to have this paper published.

\section{Competing interests}

There are no competing interests to declare.

\author{
Authors' information (optional) \\ ${ }^{1}$ Economic Department, Semnan University, Semnan-Iran \\ ${ }^{2}$ Economic Department, Semnan University, Semnan-Iran
}

\section{References}

Aggarwal, R. 1981. "Exchange Rates and Stock Prices: A Study of the U.S. Capital Markets under Floating Exchange Rates.” Akron Business and Economic Review 12: 7-12.

Abounoori, E., and M. Tour. 2019. "Stock Market Interactions among Iran, USA, Turkey, and UAE." Physica A 524: 297-305. doi:10.1016/j. physa. 2019.04 .232

Arneric, J., and B. S. Peric. 2018. "Panel GARCH model with cross-sectional dependence between cee emerging markets in trading day effects analysis.” Institute for Economic Forecasting 4: 71-84.

Bathia, D., CH. Bouras, R. Demirer, and R. Gupta. 2020. "Cross-border capital flows and return dynamics in emerging stock markets: Relative roles of equity and debt flows." Journal of International Money and Finance 109: 1-23. doi:10.1016/j. jimonfin.2020.102258.

Baybogan, B. 2013. "Empirical Investigation of MGarch Models." Journal of Statistical and Econometric Methods 2(3): 75-93.

Bollerslev, T. 1986. “Generalized Autoregressive Conditional Heteroskedasticity.” Journal of Econometrics 31: 307-327. doi:org/10.1016/ 0304-4076(86)90063-1.

Bollerslev, T., R. Engle, and J. Wooldridge. 1988. "A Capital Asset Pricing Model with Time-Varying Covariances.” Journal of Political Economy 96: 31-116. doi:org/10.1086/261527.

Bollerslev, T. 1990. "Modeling the Coherence in Short-run Nominal Exchange Rates: A Multivariate Generalized

ARCH Model.” Review of Economics and Statistics 72: 498-505. doi.org/ 10.2307/ 2109358.

Branson, W. H., and D. W. Henderson. 1985. "The Specification and Influence of Assets Markets." in R. W. Jones and P.B. Kenen (Eds), Handbook of International Economics. North-Holland, Amsterdam, 749-806.

Branson, W.H. 1983. "Macroeconomic determinants of real Exchange Rate Risk. In: Herring, R.J. (Ed.), Managing Foreign Exchange Rate Risk." Cambridge University Press, Cambridge, MA.

Cermeño, R., and K. B. Grier. 2006. "Conditional heteroskedasticity and cross-sectional dependence in panel data: an empirical study of inflation uncertainty in the G7 countries." In: Baltagi, B.H. (Ed.), Panel Data Econometrics 10: 259-278.

Dornbusch, R., and S. Fischer. 1980. "Exchange Rates and Current Account." American Economic Review 70: 960-971. 
Engle, R. F. 1982. "Autoregressive Conditional Heteroscedasticity with Estimates of the Variance of United Kingdom Inflation.” Econometrica 50(4): 987-1007. doi:org/10.2307/ 1912773.

Engle, R. 2002. "Dynamic conditional correlation: a simple class of multivariate generalized autoregressive conditional heteroskedasticity models." Journal of Business and Economic Statistics 20: 339-350. doi:org/10.1198/ 073500102288618487.

Engle, R. F., and B. Kelly. 2012. "Dynamic equicorrelation." Journal of Business \& Economic Statistics 30: 212-228. doi.org/10. 1080/ 07350015.2011.652048.

Flavin, T. J., and M. R. Wickens. 2001. "Macroeconomic influences on optimal asset allocation.” Review of Financial Economics 12: 207-231. doi:org/10.1016/S1058-3300(02)00072

Frankel, J.A. 1983. "Monetary and portfolio balance models of exchange rate Determination." In: Bhandari, J.S., Putnam, B.H. (Eds.), Economic Interdependence and Flexible Exchange Rates. MIT Press, Cambridge, MA.

Gu, H., Z. Liu, and Y. Weng, 2017. "Time-varying correlations in global real estate markets: A multivariate GARCH with spatial effects approach.” Physica A 471: 460-472. doi:10.1016/j.physa.2016.12.056.

Hamuo, Y., R. W. Masulis and Ng V. 2006. "Correlations in Pric Changes and Volatility across International Stock Markets.” The Review of Financial Studies 3(2): 281-307.

Hachula, M., and S. Hoffmann. 2015. "The Output Effects of Commodity Price Volatility: Evidence from Exporting Countries.” Free University Berlin, School of Business \& Economics, Discussion Paper.

Hammoudeh, S. M., Y. Yuan, and M. McAleer. 2010. "Exchange Rate and Industrial Commodity Volatility Transmissions and Hedging Strategies.” Working Paper.

Hassani, H., M. R. Yeganegib, J Cuñadoc, and R. Guptad. 2019. "Forecasting interest rate volatility of the United Kingdom: evidence from over 150 years of data." Journal of Applied Statistics 47(6): 11281143 doi.org/10.1080/02664763.2019. 1666093.

Hosking, J. R. M. 1980 "The Multivariate Portmanteau Statistic." Journal of the American Statistical Association 75(371): 602-608. doi:org/ 10.1080/01621459.1980.10477520.

Kanas, A. 1998. "Volatility Spillovers across Equity Markets: European Evidence." Applied Financial Economics 8: 245-256.

Lee, J. 2010. "The link between output growth and volatility: Evidence from a GARCH model with panel data." Economics Letters 106: 143-145. doi:10.1016/j.econlet.2009.11.008.

Newey, W., and K. West 1987. "A simple positive semi-definite, heteroskedasticity and autocorrelation consistent covariance matrix.” Econometrica 55: 703-708. doi:org/10.2307/ 1913610.

Ribeiro, P. P., R. Cermeno, and J. D. Curto. 2017. "Sovereign bond markets and Pnancial volatility dynamics: Panel-GARCH evidence for six euro area countries." Finance Research Letters 21(C): 107-114. doi:org/10.1016/j.frl.2016.11.011.

Worthington, A., and H. Higgs. 2004. "Transmission of Equity Returns and Volatility in Asian Developed and Emerging Markets: a Multivariate GARCH Analysis.” International Journal of Finance and Economics 9: 7180 . doi:org/10.1002/ijfe.222. 